\title{
El feminismo italiano y español de la década de 1980. Perspectivas sociales y representaciones literarias: Lettere a Marina (1981) de Dacia Maraini y Para no volver (1985) de Esther Tusquets
}

\section{Paola Susana Solorza'}

Recepción: 28 de abril de 2014 / Aprobación: 8 de junio de 2014

\section{Resumen}

Este artículo analiza los cambios que se producen al interior del movimiento feminista italiano y español de la década de 1980. Señala la diversificación del movimiento, mucho más evidente en el caso español que en el italiano, donde la heterogeneidad había venido gestándose desde los inicios de la década de 1970. El feminismo tuvo también sus resonancias en la literatura de la época. En este sentido, Lettere a Marina (1981) de Dacia Maraini y Para no volver (1985) de Esther Tusquets son representaciones literarias que utilizan como intertexto los discursos de debate social que había instaurado el movimiento, entre ellos, la crítica al modelo patriarcal del psicoanálisis, la pugna por el derecho al aborto, el lesbianismo y la necesidad de las mujeres de disponer libremente de sus cuerpos, contribuyendo así a visibilizar el terreno ganado en materia de derechos y lo que quedará todavía pendiente para décadas sucesivas.

\section{Palabras claves}

Feminismo italiano; feminismo español; derechos de las mujeres; Dacia Maraini; Esther Tusquets

\section{Abstract}

This article analyzes the changes within the Italian and Spanish feminist movements in the 80's. It explores the diversification of the feminist movement, more evident in the Spanish case than in the Italian one, where heterogeneity had been brewing from the beginning of the 70's. The feminist movement also influenced literature in those years. In this sense, Lettere a Marina (1981) by Italian author Dacia Maraini and

$1 \quad$ Argentina. Doctoranda del Instituto Interdisciplinario de Estudios de Género de la Facultad de Filosofía y Letras de la Universidad de Buenos Aires (UBA). Becaria del proyecto Universidad de Buenos Aires, Ciencia y Técnica (UBACyT) durante el periodo 2013-2016. Magíster en Estudios de Género por la Università degli Studi di Bologna, Italia y la Universidad de Oviedo, España. Profesora de Español como Lengua Segunda y Extranjera de la UBA. Correo electrónico: learningspanishba@hotmail.com 
Para no volver (1985) by Spanish author Esther Tusquets are literary representations encompassing social debate discourses established by the feminist movement as intertexts. Such discourses include criticism to the patriarchal psychoanalytic model, struggle for abortion rights, lesbianism and women's need to decide about their own bodies. Therefore, this literature contributed to expose their achievements concerning women's rights and to focus on what was yet to be done in the succeeding decades.

\section{Keywords}

Italian feminism; Spanish feminism; women's rights; Dacia Maraini; Esther Tusquets

\section{Resumo}

O presente artigo analisa as mudanças produzidas internamente no movimento feminista italiano e no espanhol nos anos 1980. Sinaliza também a diversificação do movimento, muito mais evidente no caso espanhol que no italiano, aonde a heterogeneidade veio se gestando desde o início dos anos 1970. O feminismo encontrou suas ressonâncias na literatura da época. Neste sentido, as obras Lettere a Marina (1981) de Dacia Maraini e Para no volver (1985) de Esther Tusquets são representações literárias que utilizam como intertexto os discursos de debate social que se instauraram no movimento, entre eles, a crítica ao modelo patriarcal da psicanálise, a luta pelo direito ao aborto, o lesbianismo e a necessidade das mulheres disporem livremente dos seus corpos, contribuindo assim para visibilizar o terreno ganho a partir do movimento no que se refere aos direitos e ao que ainda ficará pendente para as décadas posteriores.

\section{Palavras-chave}

Feminismo italiano; feminismo espanhol; direitos das mulheres; Dacia Maraini; Esther Tusquets

\section{¿Feminismo o feminismos? Perspectivas sociales: reivindicaciones y cambios}

a denominada "segunda ola"2 del movimiento feminista comenzó a manifestarse en el escenario europeo a inicios la década de 1970, motivada en parte por los ideales revolucionarios de mayo del año 1968. Entre los años 1970 y 1973 surgieron en Italia varios grupos y colectivos feministas que se identificaban por ciudad como, por ejemplo, el Collettivo Femminista Milanese, el Gruppo Femminista Gelese o el Collettivo Femminista Bolognese, entre otros. Italia había dejado atrás la dictadura pero las viejas estructuras patriarcales continuaban intactas, avaladas por la lglesia y los 
grupos conservadores de la sociedad, con lo cual era necesario un cambio de imaginario con respecto a los modelos de feminidad heredados.

En cuanto al contexto español, la influencia de estos ideales revolucionarios recién empezó a manifestarse a partir de 1975, al finalizar el régimen de Franco. La dictadura implicó un retroceso en todos los órdenes, España quedó aislada del resto de Europa durante casi cuatro décadas, privada de toda posibilidad de progreso. El movimiento feminista español comenzó por ello a organizarse más tardíamente, ligado al contexto político de la lucha de izquierda y la transición democrática. La doble militancia, en el partido y en el movimiento, fue central para las españolas, no ocurrió lo mismo en Italia, donde en la puja por des-identificarse de un imaginario patriarcal heredado, los diversos grupos y colectivos feministas rechazaron de manera bastante radical las estructuras políticas partidarias, como ocurrió con uno de los grupos más importantes del feminismo italiano: Rivolta Femminile, cuya principal mentora, la filósofa Carla Lonzi, en el manifiesto Sputiamo su Hegel (1970), consideraba que la lucha del proletariado no hacía más que resituar el cuerpo femenino en el ámbito privado de la familia. Lonzi propuso descolonizar el cuerpo de la mujer como punto de partida para su afirmación personal. Las italianas se alinearon, de este modo, bajo el denominado feminismo de la diferencia, que postulaba una radical des-identificación de las estructuras patriarcales. Las feministas españolas, en cambio, la mayoría de ellas vinculadas al Partido Comunista Español (P.C.E.), se consolidaron en la década de 1970 como un movimiento mucho más homogéneo, apostando por la igualdad en todos los órdenes "como una superación de los géneros en una comprensión unitaria de lo humano" (Posada Kubissa, 1998, p. 282).

Sin embargo, las jornadas celebradas en Granada, en mayo de 1979, determinaron un punto de quiebre para el movimiento feminista español: "el feminismo dejará de manifestarse como una realidad unívoca, abriéndose a la pluralidad de frentes de lucha" (Agustín Puerta, 2003, p. 309). En estas jornadas, que marcaron la ruptura organizativa, se retomó el debate de las dos corrientes enfrentadas: feminismo de la igualdad versus feminismo de la diferencia. De la primera corriente eran partidarias las seguidoras del feminismo socialista, que buscaban una sociedad en la que hombres y mujeres tuvieran los mismos derechos y obligaciones, mientras que quienes se incluían en la segunda sostenían la necesidad de que se entendiera a las mujeres no como militantes en partidos con una ideología de base netamente patriarcal, sino en tanto portadoras de una diferencia estructural irreductible al viejo imaginario. Como consecuencia, se produjo en el seno del feminismo español una dispersión de grupos y organizaciones. En la década de 1980, este carácter pluralista fue visto, por un lado, como el fin de la lucha organizada y, por otro, en términos de un enriquecimiento o de una apertura que obligó a tener en cuenta la diversidad al interior de un movimiento que se creía unívoco. 
En el contexto feminista italiano, esta heterogeneidad, como hemos mencionado, comenzó a manifestarse desde los inicios de la década de 1970. En marzo de 1983, en una conferencia organizada por mujeres del Partido Comunista Italiano (P.C.I.) también se presentó el dilema de la doble militancia: "are women in the P.C.I. feminists, or communists first, or autonomous women?" (Birnbaum, 1986, p. 250), que se retomará en otras oportunidades, quedando siempre irresuelto. En esta segunda fase del movimiento feminista italiano, prevaleció el desarrollo del asociacionismo y de los centros de mujeres, lo que marcó el cambio de un momento de mayor revolución y revuelta, como fue la década de 1970, a un estadio en el que comenzaron a volcarse las fuerzas hacia la investigación y la elaboración de una cultura de mujeres, algo que en países como los Estados Unidos había tomado la denominación de Women Studies al interior de la universidad. Sin embargo, el caso italiano fue bastante peculiar, dado que la creación de estos centros se realizó de manera autónoma, fuera de las universidades, por ejemplo, el Centro di Documentazione, Ricerca e Iniziativa delle Donne di Bologna, un proyecto llevado adelante por la Associazione Orlando con el objetivo de "fondare un'istituzione autonoma per promuovere la cultura della differenza di genere e la presenza pubblica femminile [fundar una institución autónoma para promover la cultura de la diferencia de género y la presencia pública femenina]"3 (Guerra, 2008, p. 74). En 1986, se realizó, en Siena, el Primo Convegno dei Centri delle Donne, que ya por ese entonces eran numerosos en diversas partes de Italia, para promover la historia de la lucha política, cultural y colectiva de las mujeres.

Esta etapa, que podemos denominar de "feminismo cultural", también tuvo su paralelismo en España con los "Estudios de la Mujer", que, a diferencia de lo que ocurrió en Italia, surgieron en el ámbito académico, cuando un grupo de profesoras feministas trasladaron a la teoría los orígenes y factores de la opresión de las mujeres. La filósofa Celia Amorós, entre otras, participó de esta iniciativa con el seminario "Feminismo e llustración" del Instituto de Investigaciones Feministas de la Universidad Complutense de Madrid, iniciado en el curso académico 1986/1987 (Amorós, 2008, p. 9). Como su colega, Amelia Valcárcel, Amorós ha defendido el feminismo de la igualdad: "al menos, vivir como sujetos, aun en la retorcida y sofisticada forma del deprimido que asume el discurso del otro" (Amorós, 1985, p. 75). La corriente de la igualdad entiende que no hay otra cosa más que las estructuras que nos han tocado en suerte y, por lo tanto, se debe actuar a partir de ellas. Valcárcel refuerza esta idea en El derecho al mal: "sólo queda una vía abierta... que las mujeres hagan suyo el actual código de los varones... obra mujer como un hombre haría, porque es él, hoy por hoy, el único poseedor de la universalidad" (Valcárcel citado en Agustín Puerta, p. 2009).

3 Todas las traducciones al español que se realizan a partir de aquí son mías. 
Aun actuando a partir de estas estructuras, se debe tener siempre una perspectiva crítica. Por eso, Amorós apunta, por su parte, a la necesidad de desmontar la universalidad de un pensamiento que se nos ha impuesto como "la razón tout court" y con esto, hacer visibles "las astucias interesadas del poder" (1985, p. 103).

Las adeptas al feminismo de la diferencia en España han sido minoría, pues sus postulados fueron interpretados como una vuelta a la mística de la feminidad y un peligro de esencialismo y determinismo biológico: "basta representarse el espectáculo de una manifestación de mujeres reivindicando militantemente... los valores femeninos de la dulzura, la ternura, y la emocionalidad" (Amorós, 1985, p. 134).

En Italia, en cambio, esta corriente fue la que alcanzó mayor difusión, sobre todo a través de una práctica que se consolida en este período: la del pequeño grupo de autoconciencia ${ }^{4}$, que surgió ante la necesidad de las mujeres de afirmarse a sí mismas, encontrando una forma de expresar la propia experiencia a partir de verse reflejadas y/o representadas en otras mujeres, dando lugar a esa genealogía femenina que el imaginario patriarcal ha invisibilizado y silenciado. Las feministas del grupo de la Libreria delle Donne di Milano, entre ellas Luisa Muraro, han sostenido esta postura influenciadas por el pensamiento de la filósofa y psicoanalista francesa Luce Irigaray, afirmando que la primera relación entre mujeres se da a través del vínculo madre-hija, algo que es rápidamente prohibido en el imaginario patriarcal: "nella nostra cultura, come ha sottolineato Luce Irigaray, manca la rappresentazione del rapporto madre-figlia [en nuestra cultura, como ha subrayado Luce Irigaray, falta la representación del vínculo madre-hija]" (1987, p. 10). De esta manera, la subjetividad femenina queda sin referente, negada "la mujer renuncia sin saberlo a la especificidad de su imaginario" (Irigaray, 1974b, p. 149). Con este trasfondo ideológico, en 1983, las feministas Luisa Muraro y Chiara Zamboni fundaron el grupo Fontana del Ferro, que un año más tarde se transformó en la comunidad filosófica Diotima de la Universidad de Verona ${ }^{5}$, cuyas ideas de base quedaron registradas en el primer libro del grupo: Il pensiero della differenza sessuale (1987): "produrre noi stesse i testi su cui lavorare, senza passare attraverso il commento di testi altrui e senza fare riferimento a posizioni filosofiche già definite, ma avvalendoci piuttosto del sapere guadagnato dal movimento politico delle donne [producir nosotras mismas los textos sobre los cuales trabajar, sin pasar a través del comentario de los textos de otros y sin hacer referencia a posiciones filosóficas ya definidas,

$4 \quad$ Esta práctica de la autoconciencia, surgió en los Estados Unidos hacia fines de la década de 1970 y ejercerá una enorme influencia en el feminismo italiano del decenio siguiente (Librería delle Donne di Milano, 1987, p. 32).

5 Diotima de Mantinea es nombrada por Sócrates en el Banquete de Platón como aquella que le habría enseñado la mayeútica filosófica. Ha sido, por tradición, considerada un personaje imaginario; sin embargo, desde 1960, filósofas e historiadoras como Mary Ellen Waithe (1992, pp. 83-116) se han inclinado a pensar que existió realmente. 
sino valernos más bien del saber adquirido por el movimiento político de las mujeres]" (Libreria delle Donne di Milano, 1987, p. 177).

Diotima buscó recrear un imaginario femenino a partir del cual las mujeres lograran auto-representarse; en otras palabras, se trató de atravesar la cultura dada para producir nuevas interpretaciones del mundo, a través de la experiencia que han denominado affidamento, traducida como un "encomendarse" de las mujeres entre sí a través del amor y la confianza entre iguales (Bocchetti, 1996, p. 23). También el Centro Culturale Virginia Woolf (Università delle Donne) fundado en Roma, en 1979, desarrolló su actividad a lo largo de la década de 1980, siguiendo esta práctica del pequeño grupo de autoconciencia y del affidamento: "tenemos que ser traídas al mundo por mujeres, tenemos que inventar junto con nuestras semejantes el mundo de significaciones que constituya otro orden simbólico" (Bocchetti, 1996, pp. 21-22), lo cual refiere al orden simbólico de la madre ${ }^{6}$, en contraposición al orden simbólico del padre, dando cuenta de la necesidad de una genealogía femenina. Esta corriente de la diferencia, si bien ha sido rechazada por la mayoría de las feministas españolas, tendrá, sin embargo, su influencia en un grupo de la Universidad de Barcelona, Duoda, que va a operar como punto de contacto y de intercambio con el feminismo italiano, particularmente con el Grupo de la Libreria delle Donne di Milano y la comunidad filosófica Diotima. Duoda nació en 1989 de la transformación del Centre d'Investigació Històrica de la Dona (C.I.H.D.), que en 1982 fundaron un grupo de historiadoras, alumnas y profesoras de la Universidad de Barcelona ${ }^{7}$. El intercambio ha sido posible a partir del estrecho vínculo de conocimiento y amistad entablado por María Milagros Rivera Garretas, fundadora y directora del grupo, y la feminista italiana, Luisa Muraro. El debate sobre los alcances de la corriente de la igualdad y la diferencia se encontrará siempre presente: "la fuerza de la igualdad podemos aprovecharla para mejorar nuestras vidas y nuestro mundo común si nos tomamos la libertad de la diferencia" (Jourdan, 2010, p. 59).

De forma paralela a esta etapa de feminismo cultural, con la organización de distintos grupos, promotores del conocimiento y saber de las mujeres, a través de corrientes de pensamiento enfrentadas, en la década de 1980, se produjo además en España lo que se conoció como "la institucionalización del movimiento” (Folguera, 1988, p. 127 y Blanco Corujo, 1995, p. 23), con la

6 En la década posterior, Luisa Muraro publicará su famosa obra L'ordine simbolico della madre (1991), afirmando que ha aprendido de la política de mujeres que estas, para su libre existencia, necesitan de la potencia materna, es decir, de un estadio de reconocimiento en otra/s mujer/es. El concepto de madre y/o materno, en este caso, no se reduce a lo meramente biológico sino a la relación con una mujer que actúa como transmisora de una experiencia y una genealogía femeninas: "occorre lottare perché il principio materno non sia sostituito dalla síntesis del potere costituito [es necesario luchar para que el principio materno no sea sustituido por la síntesis del poder constituido]" (p. 104) .

7 Tomaron el nombre Duoda de la condesa de Barcelona del siglo IX, ejemplo de fuerza de voluntad y de lucha, que escribió la obra: Liber manualis -que significa "libro para tener a mano"- con el objetivo de que sus hijos, Guillem y Bernat, que le habían sido arrebatados por su padre, no la olvidaran y se educaran según sus deseos. 
incorporación oficial de la problemática de las mujeres en el ámbito gubernamental. En 1983, el primer gobierno del Partido Socialista Obrero Español (P.S.O.E.) creó el Instituto de la Mujer -que, adscrito en sus comienzos al Ministerio de Cultura, pasó en 1988 a integrarse en el Ministerio de Asuntos Sociales- con la finalidad de desarrollar el principio de no discriminación previsto en la Constitución de 1978, motivando la participación de las mujeres en la vida política, cultural y económica. De aquí surgió también el programa de Política Institucional para la Igualdad de Oportunidades de las Mujeres (P.I.O.M.) (Blanco Corujo, 1995, p. 140), cuya primera etapa tuvo lugar entre los años 1988-1990. Otra faceta importante de este feminismo institucional debe situarse en los Departamentos de la Mujer de las diversas comunidades autónomas españolas. De modo similar, en Italia, se desarrolló el programa de pari opportunità a través de la política oficial, aunque su eficacia fue criticada por las feministas por no responder en la práctica a las necesidades reales de las mujeres. También las feministas españolas mantuvieron una relación tensa con las instituciones pero, en parte, cedieron al intercambio, pues: "los grupos feministas necesitaban de la infraestructura y el respaldo que las instituciones podían brindarles y estas últimas, por su parte, necesitaban contar con la base social que les proporcionarían los grupos feministas" (Agustín Puerta, 2003, p. 336).

El feminismo no se había planteado con demasiado acuerdo la cuestión del lesbianismo en sus inicios y las reivindicaciones en torno al cuerpo y la sexualidad estuvieron enfocadas exclusivamente en las relaciones heterosexuales, lo que ya a fines de la década de 1970 había comenzado a ser criticado por las feministas lesbianas. En junio de 1980, se celebraron en Madrid los Primeros Encuentros Estatales de Lesbianas. En 1981, tuvieron lugar en Valencia las II Jornadas de Lesbianismo y por ese entonces ya comenzaba a apreciarse una evolución en el tratamiento de la cuestión, aunque fue en las Jornadas de Sexualidad del año 1983 cuando se presentó el cambio más significativo. En ellas el Colectivo de Feministas Lesbianas de Madrid planteó por primera vez, de manera pública, la necesidad de un rechazo claro y rotundo de la heterosexualidad como norma.

También en Italia las feministas lesbianas alcanzaron mayor visibilidad en la década de 1980, momento en el cual "il silenzio e la rimozione che aveva coperto l'esperienza lesbica cominciò ad infrangersi [el silencio y la marginación que había implicado la experiencia lesbiana comenzó a quebrarse]" (Guerra, 2008, p. 75). En diciembre de 1981, en la Casa delle Donne de Roma, se celebró un congreso de feministas lesbianas, y al año siguiente, el colectivo Vivere Lesbica, publicó un número de la revista Differenze, en donde se recogían frases como: "uscite da corpi ben vivi, da un fervore politico assai grande [salidas de cuerpos bien vivos, de un fervor político muy grande]" (cit. en Guerra, 2008, p. 76). En 1985, se tradujo al italiano el texto de Adrienne Rich: Eterossesualità obbligatoria ed esistenza lesbica, que ha ejercido su influencia 
sobre las feministas lesbianas. Alli se plantea la existencia de un continuum lesbiano, que no se reduce a la preferencia o inclinación sexual, sino que incluye la mencionada práctica del affidamento, esa confianza y complicidad que surge en las relaciones entre mujeres: "questo potenziale... può essere messo a disposizione della volontà di trasformazione propria del femminismo [este potencial... puede ser puesto a disposición de la voluntad de transformación propia del feminismo]" (Guerra, 2008, p. 235).

El aborto constituyó otro de los temas claves en lo que respecta a la reivindicación del derecho al propio cuerpo, y si bien en Italia ya se había producido un avance en la legislación en 1978, en España era algo que todavía estaba pendiente. Recién en 1979, a raíz del famoso juicio a las once mujeres de Bilbao que habían abortado en un estado de extrema necesidad, se convirtió en una cuestión política de primer interés ${ }^{8}$. Las feministas se movilizaron para liberar a las condenadas -siendo esta una de las últimas ocasiones en que el movimiento, ya dividido, decidía unirse ${ }^{9}$ - y redactaron un documento firmado por más de un centenar de mujeres, entre ellas algunas de gran popularidad como Ana Belén, Maruja Torres o Rosa María Sardá, que en un gesto de apoyo afirmaban: "yo también he abortado" (Blanco Corujo, 1995, p. 118 y Agustín Puerta, 2003, p. 226). La Iglesia Católica continuó ejerciendo una oposición feroz a la legalización del derecho al aborto y, en $1983^{10}$, se hizo público un proyecto de ley elaborado por el P.S.O.E. que planteaba la despenalización de esta práctica en tres supuestos: aborto terapéutico (en caso de peligro para la vida o salud de la embarazada), aborto ético (cuando el embarazo es consecuencia de una violación que ha sido denunciada y siempre que la intervención quirúrgica se lleve a cabo dentro de las doce semanas de gestación), y aborto eugenésico (en caso de malformación del feto). El proceso de aceptación de la ley de aborto fue largo ${ }^{11}$; finalmente será aprobada por el parlamento español el 5 de julio de 1985. Al igual que en el caso italiano, se incorporó el derecho a la objeción de conciencia, lo que constituyó el principal impedimento para

8 El juicio a las "once de Bilbao" mantuvo en vilo a una sociedad que durante años había impuesto un férreo pacto de silencio sobre un problema tabú. Se realizó una campaña de amnistía para las condenadas ligada al derecho al "aborto libre y gratuito", lo cual contribuyó a que las mujeres fueran indultadas e impulsó en los años sucesivos la legalización del aborto.

9 Como afirma Agustín Puerta, "Las movilizaciones en torno al tema del aborto permitieron una progresiva recomposición de fuerzas, que consiguió mantener la presencia pública de las feministas” (2003, p. 313).

10 Esther Tusquets escribe un interesante artículo en prensa a propósito de los excesos delirantes de los antiabortistas en 1983 y cita el caso de "un brillante licenciado y alto ejecutivo de un grupo editorial, [que] argumenta ante todo el que quiera escuchar, que una violación, aun siendo lamentable, constituye un delito menos pecaminoso y desagradable a Dios que la masturbación: en la violación, bien que mal, los espermatozoides pueden llegar a destino, mientras que en la masturbación se malogran. ¡O sea que la violación se justifica en parte porque la mujer violada, con un poco de suerte, puede quedar embarazada de su violador!" (2006, p. 125).

11 La ley de aborto fue modificada por el P.S.O.E. mediante la introducción de un sistema de plazos que declara el aborto libre hasta las 14 semanas de gestación, período durante el cual la mujer puede abortar sin dar explicaciones y sin necesidad de autorización. Los detractores, aún hoy ven el aborto como un retroceso a la época de la barbarie y el actual Partido Popular ha intentado derogar la ley. 
la aplicación de la ley: "creándose una doble situación... en donde muchos médicos se acogían a la cláusula de objeción de conciencia en los centros públicos, mientras practicaban luego abortos en clínicas privadas" (Agustín Puerta, 2003, p. 232).

Otra cuestión que se debatió en este período fue la de la violencia contra las mujeres. Se planteó en los distintos grupos y colectivos la necesidad de desarrollar un trabajo específico en torno a esta problemática y desde el ámbito institucional se puso en marcha, a partir de 1984, una campaña contra los malos tratos a las mujeres. Sin embargo, no será suficiente, dado que "esta violencia tiene una finalidad correctiva de posturas rebeldes... juega [por lo tanto] un papel fundamental en el mantenimiento del orden patriarcal" (Agustín Puerta, 2003, p. 243). Por su parte, en el parlamento italiano, se reabrió en 1989, la discusión sobre la ley contra la violencia sexual, lo cual determinó la necesidad de "un principio de justicia femenino": "lo que no soportamos, digámoslo finalmente, es que los estupradores sean juzgados por otros hombres, según sus leyes" (Bocchetti, 1996, p. 212). Algo que va a seguir siendo tema de debate en la década sucesiva.

Hacia fines de la década de 1980, en el feminismo italiano se produjeron algunos quiebres y la discusión con las mujeres del P.C.I. se cerró definitivamente en 1988. Aquellas que creían en la fuerza transformadora de la subjetividad femenina -feminismo de la diferencia- siguieron manifestando que el interés político de las comunistas solo adquiría fundamento en la tradición del partido, y tendían, por ende, a repetir viejas estructuras.

Hemos visto que el movimiento feminista español se diversificó en esta década como lo había hecho el movimiento de mujeres en Italia en la de 1970, lo cual da cuenta, en ambos casos, de los complejos mecanismos de representación, que no deben ser homogéneos si lo que se pretende es elaborar una estrategia democráticamente inclusiva para representar no a la mujer en tanto que estereotipo de un discurso hegemónico, sino a las mujeres, sujetos reales de su propia historia. Amorós afirma en este sentido que "el feminismo no es un término unívoco, de hecho... se habla, simplemente, en plural, de 'feminismos'” (2008, p. 353). El reto para el movimiento de este período será saber combinar eficazmente el binomio unidad/diversidad.

\section{Representaciones literarias y feminismo: Lettere a Marina y Para no volver}

Los debates sociales y políticos sostenidos por el movimiento feminista tuvieron su influencia en la producción literaria de la época. Centrándonos en la década de 1980 en Italia, escritoras reconocidas como Natalia Ginzburg con su novela La città e la casa (1984) o Elsa Morante con Aracoeli (1982), hacen referencia a la crisis de los roles tradicionales, mediante personajes femeninos 
fuertes, en espacios donde se percibe la ausencia de la figura paterna y aparece la representación de una sexualidad diversa, libre, sin opresiones.

En España, durante la década de 1980, se produjo una renovación artística que dio lugar a una gran producción literaria femenina, anteriormente silenciada por el franquismo. Muchas de las escritoras de este período se confiesan feministas e incorporan a sus obras perspectivas de emancipación de las mujeres como es el caso, por ejemplo, de Josefina Aldecoa y su novela La enredadera (1984), donde juega con el estereotipo femenino de la esposa fiel, oponiéndole la figura de la mujer intelectual e independiente. Soledad Puértolas en su obra Queda la noche (1989) presenta una protagonista femenina que cuestiona constantemente su posición en la sociedad. Por su parte, Ana María Moix en uno de los relatos de su libro Las virtudes peligrosas (1985), retoma una cuestión muy presente en las disputas feministas de esa época en relación con la diversidad sexual y el lesbianismo, con una protagonista que recuerda su pasión por una mujer.

Dentro de este panorama literario, se destacan paralelamente dos escritoras que han mostrado, cada una a su modo, a lo largo de su producción, una clara toma de conciencia con respecto a las situaciones de opresión y de lucha que han vivido las mujeres: la italiana Dacia Maraini, quien desde sus inicios en la literatura manifestó un fuerte compromiso social, formó parte del grupo Rivolta Femminile y en 1973 fundó la Asocciazione della Maddalena, compuesta por tres grupos que se ocupaban de la gestión de un teatro de mujeres, de la Rivista Femminile Effe y de una librería de textos feministas. Asimismo, la escritora española Esther Tusquets, nacida en el seno de una familia franquista, y habiéndose declarado desde temprana edad en rebeldía con la ideología familiar, aun cuando no haya sido activista al interior del movimiento de mujeres, va a presentar a lo largo de toda su obra una preocupación constante por la condición femenina.

En 1981, se publica en Italia Lettere a Marina de Dacia Maraini, una novela que podríamos denominar "epistolar", compuesta de un conjunto de cartas que la narradora, Bianca, le escribe a su amiga Marina, y que probablemente nunca sean enviadas: "queste lettere che non so neanche se ti manderò mai [estas cartas que no sé ni siquiera si te enviaré alguna vez]" (Maraini, 2008, p. 5). El formato epistolar funciona como un tipo de escritura que permite la confesión y la reflexión de la narradora sobre los acontecimientos que han formado parte de su vida, como un momento de auto-análisis que Bianca se concede, bajo la forma de un diálogo con una interlocutora ausente. Maraini afirma al respecto: "volevo un tono che solo le lettere possono dare, quel sentirsi ed essere a tu per tu [quería un tono que solo las cartas pueden conceder, ese sentirse cara a cara y darse de tú a tú]" (Maraini citada en Sumeli Weinberg 1993, p. 80). Para que la reflexión sea posible, Bianca necesita tomar distancia de los hechos; por eso, desde que inicia su escritura sabemos que se encuentra en un lugar solitario, en una casa que alquiló para alejarse 
de todo, particularmente de Marina, durante tres meses. El comienzo de la novela da indicios claros del tipo de relación que une -o unió- a Bianca y Marina: "abbiamo deciso di non fare più l'amore, Marina [hemos decidido no hacer más el amor, Marina]" (Maraini, 2008, p. 13). Esa relación es considerada por Bianca en términos de "una seduzione libertina [una seducción libertina]" (Maraini, 2008, p. 6) por transgredir la norma. Hemos visto que en Italia -al igual que en España- fue en la década de 1980 cuando el lesbianismo se volvió más visible y dejó de estar relegado al silencio. Maraini es consciente de esto y en una entrevista afirma con respecto al momento de publicación de la novela y su contenido:

Quella era un'epoca in cui si esplorava la molteplicità delle esperienze sessuali... Ho raccontato questa storia perchè mi sta a cuore il problema che riguarda ruoli, sessualità, rapporto dei generi. Ci riguardano da vicino come donne e il nostro stare nel sociale passa attraverso questo [Aquella era una época en la cual se exploraba la multiplicidad de las experiencias sexuales... He contado esta historia porque me llega profundamente el problema que concierne a los roles sociales, la sexualidad, la relación entre los géneros. Nos toca muy de cerca como mujeres y nuestro estar en lo social pasa a través de esto] (Maraini citada en Puccio, 2006, p. 1).

La reflexión de Bianca sobre su relación con Marina implica una crítica y una transgresión de la norma socialmente acatada en las relaciones de parentesco, una estrategia que deconstruye el modelo impuesto por el psicoanálisis y es algo que se corresponde, a su vez, con la propuesta que han llevado adelante las feministas italianas en este período a través de la práctica del affidamento, mencionada anteriormente. La entrada a lo que en términos lacanianos denominamos el orden simbólico, orden del padre o del lenguaje, supone para el género femenino la forclusión de una figura fundamental, la madre: "durante la... fase edípica domina el deseo de ver desaparecer a la madre para así reemplazarla junto al padre" (Irigaray, 1974a, p. 121). Esta forclusión es lo que provoca en la niña la renuncia a la especificidad de un imaginario femenino y la entrada en un orden masculino, en el cual su subjetividad carece de referente. Irigaray afirma que, de este modo, la mujer es "convertida a un discurso que niega... su placer, inscribiéndola como vacío, revés, negativo... en pro del falo" (1974b, p. 157). El deseo reprimido que se pone de manifiesto en la relación entre Bianca y Marina se revela justamente a través de una apropiación de los roles madre-hija. Bianca afirma en una de sus cartas: "scappo per il tuo testardo e malandrino desiderio di farmi madre contro ogni mia voglia [escapo por tu testarudo y maldito deseo de hacerme madre contra mi voluntad]" (Maraini, 2008, p. 7). Aún cuando niegue en una primera instancia su voluntad de transformarse en madre de su amante, en un juego complejo de amor y de incesto, su negación no será otra cosa que la manifestación de un deseo reprimido que en todo momento luchará por salir a la luz. De hecho, era ya portadora de un amor incestuoso hacia su propia madre:

Ho ripensato a come guardavo la pelle lunare di mia madre mentre si faceva il bagno. Di come ho desiderato la sua bocca di geranio quando si chinava su di me 
che fingevo dormire... Chi vuoi sposare tu? Mamma. Non si può. Allora papà [He vuelto a pensar en cómo observaba la piel lunar de mi madre mientras se bañaba. En cómo he deseado su boca de geranio cuando se reclinaba hacia mí, mientras yo fingía dormir... ¿Con quién te quieres casar? Mamá. No se puede. Entonces papá] (Maraini, 2008, p. 129).

Bianca es consciente de las prohibiciones y del modelo cultural impuesto que la obligan a normalizar su deseo. El amor imposible hacia su madre la ha llevado a concretar ese deseo en otra figura femenina, Marina, de la cual también intenta escapar, alejándose:

Come con mia madre c'è un'ombra che mi separa da lei: una tentazione antichissima di incesto. L'orrore a trovarmi la carne della mia carne fra le labbra. Per questo chiudo porte metto sedie tappeti fra me e lei [Como con mi madre hay una sombra que me separa de ella: una tentación antiquísima de incesto. El horror a encontrar la carne de mi carne entre los labios. Debido a esto cierro puertas meto sillas alfombras entre ella y yo] (Maraini, 2008, p. 197).

Aun así, fantasea a cada momento con que Marina finalmente la encuentre. El aislamiento voluntario de Bianca es producto de la influencia que ejerce sobre ella el imaginario, y va a permanecer en aquella casa hasta lograr liberarse de una parte de sí que considera anómala: "finché mi sarò liberata di una parte di me che mi è estranea [Hasta que me haya liberado de una parte de mí que me resulta extraña]" (Maraini, 2008, p. 22).

En Para no volver, la protagonista, Elena, también experimenta esa permanente sensación de extrañeza ante una sociedad que le impone cumplir con las prerrogativas asignadas a su género: "Elena, siempre a caballo entre dos mundos, siempre fuera de lugar y sin saber cuál era exactamente el que le correspondía" (Tusquets, 2005, p. 48). Es este estado el que la lleva a psicoanalizarse, resistiéndose, sin embargo, a la relación asimétrica de poder que establece con su psicoanalista: “¿qué había en el psicoanálisis que la impulsaba, de forma casi inevitable a comportarse como una niñata estúpida?" (Tusquets, 2005, p. 22). Molinaro afirma que lo que aquí se cuestiona es el proceso de normalización que lleva a cabo el psicoanálisis: "the functions of control... that characterize the discipline of psicoanálisis [las funciones de control... que caracterizan la disciplina del psicoanálisis]" (1991, p. 89). Al igual que en Lettere a Marina, la cuestión del cuerpo y las prohibiciones del incesto en función de roles pre-determinados, surgen en los recuerdos de infancia:

Cuando eran todavía unos niños y querían trasladarse a la cama de sus padres... todos promiscuamente juntos y revueltos... ya desde muy chica la había entristecido que el término de la jornada impusiera que debían separarse los unos de los otros y dormir cada uno en su propia cama (Tusquets, 2005, pp. 24-25).

La narración se encuentra en tercera persona, aunque el uso de la técnica narrativa conocida como el fluir de conciencia, a través de un interminable discurso de estilo indirecto libre, determina un proceso de apropiación de la palabra por parte de la protagonista. Elena es una mujer de 50 años, casada 
con Julio, un destacado director de cine, siempre de gira, que la engaña con mujeres más jóvenes ${ }^{12}$. Sus hijos, Pablo y Jorge, ya adultos, han dejado la casa de sus padres. Es esta sensación de vacío, producto de la soledad, lo que a Elena la sume en una depresión que la lleva a reflexionar sobre el rumbo que ha tomado su vida.

La pertenencia de clase y la crítica al origen se manifiestan como en la primera novela publicada por Tusquets, El mismo mar de todos los veranos (1978), "había nacido... en la burguesía, también ella una niñita bien" (2005, p. 49). Unido a ello, la mención del franquismo como modelo de la generación de sus padres, que Elena debió aceptar desde la infancia: "la propia Elena, pues, creciendo... en el franquismo de los cuarenta, de los cincuenta" (2005, p. 45). Su presente, si tenemos en cuenta que tiene 50 años, corresponde al momento temporal que nos compete, la década de 1980, pues "había nacido... en el primer año de la guerra civil" (Tusquets, 2005, pp. 44-45). Además, sabemos que Elena ha entrado en contacto con las ideas del feminismo: "tan justa la causa del feminismo, tan básicamente justa, le parece" (Tusquets, 2005, p. 68).

El psicoanálisis y el feminismo se presentan en la novela como teorías enfrentadas y la reticencia de Elena a aceptar las palabras de "el Mago", uno de los tantos sobrenombres irónicos que le adjudica a su psicoanalista argentino para burlarse del poder que ejerce sobre ella ${ }^{13}$, muestra los términos en que dicha confrontación se lleva a cabo, explicitando "las zarandajas múltiples que hayan podido inventar Papá Freud y Tío Lacan" (Tusquets, 2005, p. 157), entre ellas, la envidia del pene. El Mago le insinúa que puede estar padeciendo consciente o inconscientemente de esta envidia, cuando ella le cuenta el modo en que su amigo Eduardo bromea sobre sus inclinaciones feministas: "aquello que ninguna mujer podrá hacer jamás es dibujar meando un ocho en la pared" (Tusquets, 2005, p. 61). La relación que Elena establece con su cuerpo es conflictiva y en su búsqueda personal inciden, sin duda, los estereotipos que instaura el imaginario. El temor a la vejez es uno de ellos. Se ve "como una mujer ridícula que no ha sabido, no está sabiendo, correctamente envejecer, al borde de la menopausia y sin haber superado en ningún momento la adolescencia, sin haberse convertido para casi nada en una mujer adulta" (Tusquets, 2005, p. 25).

El título de la novela da cuenta, en efecto, de un tiempo que se ha ido para no regresar, alude a una pérdida que es justamente la juventud pasada de

12 Es costumbre de Tusquets utilizar personajes prototípicos que no se limitan a una sola novela, sino que reaparecen en otras posteriores: el marido de Elena posee características idénticas al de Elia en El mismo mar de todos los veranos, de hecho ambos personajes tienen el mismo nombre.

13 Lo llamará "el Impasible", "el Llanero Solitario de la Pampa", "el Mago-Domador", "el Exorcista", "Cara de Palo" (Tusquets, 2005, pp. 38-39 y pp. 112-135). En Confesiones de una vieja dama indigna, el Mago aparece como un personaje real en el que la autora se ha inspirado, un psicoanalista argentino con el que se analizó cinco años, "Jorge Belinsky, a veces llamado el Flaco, a veces llamado Bubú, a veces llamado el Mago ... Fue una suerte conocerle y una suerte tenerlo como psicoanalista, aunque yo establecí desde el primer día una resistencia feroz" (2009, p. 337). 
Elena. El epígrafe reafirma esta idea mediante unos versos de Darío: "Juventud, divino tesoro, ya te vas para no volver" (Darío citado en Tusquets, 2005). Molinaro sugiere al respecto: "all that remains is an incomplete lamentation on present loss or an implicit command to move forward [lo único que queda es una incompleta lamentación con respecto a la pérdida presente o una orden implícita de avanzar]" (1991, p. 87). La sensación de vejez afecta el cuerpo de Elena y la imagen que tiene de él; le resulta inevitable compararse con la joven esposa de su hijo Pablo, que parece encarnar la perfección no solo en tanto estereotipo del cuerpo bello, sino porque se adecua perfectamente a su rol al interior de la familia: "[Pablo] casado con esa muchachita que se diría salida de una película de dibujos animados... la mamá perfecta en technicolor... una mamá empeñada desde el principio en que le dieran el Oscar a la mejor madre del año" (Tusquets, 2005, pp. 33-34).

La crítica de Elena a la esposa de su hijo es una proyección de su propia inadecuación en una sociedad que le propone un modelo identitario que ella nunca ha podido, ni podrá, encarnar. Forma parte de lo que podemos denominar un cuerpo resistente a la norma o un cuerpo que falla en la repetición del discurso normativo y, por consiguiente, en la consolidación de la ley de género (Butler, 2007, p. 94). En lo que refiere al paso del tiempo, Elena pone de manifiesto: "the individual struggle to maintain a balance between the external stereotypes of age-appropriate behavior and the subjective experience of the self [la lucha individual para mantener el balance entre los estereotipos externos en lo que concierne a un comportamiento adecuado a su edad y la experiencia subjetiva del ser]" (Featherstone, 1999, p. 378). Por momentos, el estereotipo de juventud y belleza la perturba: "saber que la aprecian por su inteligencia, por su honestidad, por su sentido del humor y no por su cabello o por sus piernas ... se siente absolutamente celosa y mezquina" (Tusquets, 2005, p. 78). A través del matrimonio, ciertos aspectos de la norma han logrado materializarse en ella, incidiendo en la postergación de su deseo:

Por qué motivo no ha terminado ella jamás uno de los tantos libros comenzados, no se ha decidido jamás a editarlos, no puede deberse sólo a que Julio y los hijos y el trabajo en la productora le hayan parecido siempre más importantes y hayan pasado siempre por delante de su escritura (Tusquets, 2005, p. 58).

Como hemos visto, en Lettere a Marina, Bianca también posterga su deseo, y no solo mediante el encierro voluntario, que la aísla de su amante Marina, sino en un juego constante de tensión entre prácticas conservadoras de la norma y prácticas subversivas. Antes de iniciar su relación con Marina, ha mantenido un vínculo de amor heterosexual durante tres años y tuvo un embarazo que terminó con un aborto espontáneo: "mi hanno detto che era morto e che bisognava tirarlo fuori [Me dijeron que estaba muerto y que había que sacarlo]"14 (Maraini,

14 El aborto es un tema recurrente en la obra de Maraini y además de funcionar como denuncia de la condición femenina, mediante la representación de abortos clandestinos, es un dato autobiográfico, pues se sabe que la propia autora ha debido pasar por la dolorosa experiencia de un aborto espontáneo en su 
2008, p. 16). Durante su estadía en aquella casa alejada, Bianca entabla otra relación heterosexual con el empleado de un bar, Damiano. Sin embargo, su atracción hacia Marina seguirá intacta; a pesar de la distancia, constantemente se va a comunicar con Giorgia, una amiga que ambas tienen en común, para tener noticias suyas. El recuerdo de la relación entablada con Marina trae a colación una práctica sexual fluida, líquida (Irigaray, 1990 y Wittig, 1977), en contraposición a la fijeza de la heterosexualidad como norma. El nombre de "Marina" es asimismo sinónimo de ello:

Era una esperienza strana liquida... Tu eri la marina splendente di chi mi trovavo davanti nel momento giusto per fare il bagno purificatore... Solo di una cosa avevo paura. II momento in cui mi sarei trovata a tu per tu con il tuo sesso... una piccola vongola rosata colta nel profondo del mare che si apriva sotto le mie dita curiose [Era una experiencia extraña líquida... Tú eras la marina esplendorosa delante de la cual me encontraba en el momento justo para hacer un baño purificador... Solo de una cosa tenía miedo. Del momento en el cual me encontraría frente a frente con tu sexo... una pequeña almeja rosada recogida en lo profundo del mar que se abría entre mis dedos curiosos] (Maraini, 2008, p. 33).

Resulta interesante prestar atención al modo en que la narradora representa dicha práctica en la escritura, subvirtiendo a su vez la gramática, con la omisión de los signos de puntuación. La fluidez transgrede, de este modo, los límites del lenguaje, dado que este responde a un orden o imaginario masculino incapaz de expresar la subjetividad y sexualidad femeninas. Properzi Nelsen afirma que se trata de "an indication of a mode of writing that is subversive and deconstructive [la indicación de un modo de escribir que es subversivo y deconstructivo]" (2000, p. 81). Sugiere una práctica asimilable a la que sostienen las teóricas de la ècriture fémenine, es decir, la posibilidad de inventar nuevas formas de expresión de lo femenino incluso al interior de un sistema falogocéntrico (Jones, 2001, p. 44). Irigaray alude, siguiendo esta misma línea, a la cuestión de la inadecuación del lenguaje y a la necesidad de utilizarlo, a pesar de todo, siendo conscientes de dicha falencia: "yo lo utilizo, aunque esté convencida de que el medio es ya una limitación para lo que tengo que decir, sobre todo en tanto que mujer" (1992b, p. 49).

En Lettere a Marina, la reflexión en torno a un imaginario que limita la experiencia femenina se lleva a cabo a través de la práctica del pequeño grupo de autoconciencia al que la narradora-protagonista solía acudir una vez por semana. Bianca recuerda en sus cartas los intercambios entre mujeres, donde se discute la cuestión del lenguaje y la representación. Chantal actúa como una de las madres-guía del grupo afirmando: "dire di me donna con una lingua maschile è una miserabile contradizione [decirme como mujer en una lengua masculina es una miserable contradicción]", a lo que Bianca responde: "non conosco altra lingua Chantal [no conozco otra lengua Chantal]" (2008, p. 39), lo que nos remite nuevamente a las palabras de Irigaray y la tensión existente

séptimo mes de embarazo, cuando se encontraba casada con el pintor Lucio Pozzi. 
entre la necesidad de expresarse de las mujeres y un medio lingüístico inadecuado: "el femenino en nuestras lenguas se ha convertido en un no-masculino, es decir, en una realidad abstracta sin existencia" (1992a, p. 18). Las mujeres del pequeño grupo de autoconciencia, entre ellas: Annangela, Violetta, Rita, Pina, Fiammetta, Alda y Bice, forman una especie de hermandad o sorellanza (Maraini, 2008, p. 35), a partir de la cual comparten experiencias que en el imaginario patriarcal son silenciadas. Casi todas han sufrido abusos sexuales por parte de hombres de la propia familia y sus inevitables consecuencias: "aborti emorragie gravidanze non volute [abortos hemorragias embarazos no deseados]" (Maraini, 2008, p. 44). En el cuerpo se materializan los efectos agraviantes de la norma, "el factor del dominio que ejerce el poder" inscribiéndose en la carne (Butler, 2002, p. 62).

El pequeño grupo de autoconciencia surge porque las mujeres necesitan verse reflejadas en la experiencia de sus semejantes. En Para no volver, a Elena se le plantea, ante la resistencia en la relación con su psicoanalista-hombre, la cuestión de que quizás hubiese sido mejor psicoanalizarse con una mujer, para poder sentir esa complicidad y verse mejor representada: "y nace ahora el resquemor, la sospecha, de que tal vez hubiera sido preferible analizarse... con una mujer" (Tusquets, 2005, p. 52). Sin embargo, ya ha establecido una relación de dependencia con el Mago: "Como un perro maltratado por su dueño... un ridículo perro que detesta y ama alternativa y simultáneamente a un dueño cruel al que jamás entiende y del que depende sin remedio" (Tusquets, 2005, p. 27).

El único que por momentos puede sacarla de ese "diván-escenario" (Tusquets, 2005, p. 43) es su amigo Eduardo: "Eduardo-aspirina, Eduardo-enfermero... un Eduardo capaz de olvidar transitoriamente sus problemas para ocuparse de los ajenos" (Tusquets, 2005, p. 85). Solo él logra arrancarla de las convenciones. En la novela, tanto Eduardo como Andrea -también del grupo de los viejos amigos de universidad- funcionan como opuestos complementarios de la protagonista; ambos encarnan un nivel de transgresión de las viejas estructuras del que Elena no se cree capaz:

Podría decirse respecto a Andrea o incluso a Eduardo, no les da envidia Elena por su mayor belleza, por su mayor talento... que pueden o no ser mayores que los suyos, sino por su audacia, por la plenitud de su pasión... por ser capaces de remontarse en altísimos vuelos sin comprobar previamente -como lo haría sin lugar a dudas Elena...- el estado del paracaídas o el funcionamiento del motor (Tusquets, 2005, p. 144).

Sin embargo, Elena logrará revertir su situación al conocer a Arturo, un músico argentino que se convierte en su amante. Al inicio de la relación, el deseo en ella aparece todavía reprimido y se muestra en una actitud pasiva:

Y ahora tú te pones así, linda, y yo te hago esto y lo de más allá y tú sientes eso y lo otro y te das cuenta de lo rico que es... De modo que no le parecía 
a Elena-robot, Elena-muñeca-de-porcelana, Elena-de-trapo, que estuvieran haciendo de veras el amor (Tusquets, 2005, p. 129).

Pero luego decide dejar de postergarse y toma la iniciativa:

Y se da cuenta de lo que sucede, advierte atónita -como si se tratara de un rumor oscuro y confuso que nace de las más hondas cavernas de los intrincados laberintos de ese total desconocido que es para Elena su cuerpo, un temblor imperceptible, casi ilocalizable, apenas detectable, pero que anuncia sin posible error la proximidad creciente e incontenible de la tromba marina o el huracán- la presencia incuestionable del deseo, ese deseo tan poco frecuente en ella desde hace años... ese deseo que ha ido desapareciendo en sus relaciones con Julio... deseo que preludia el goce... (Tusquets, 2005, pp. 179-180).

Cabe señalar las similitudes en el tratamiento y representación del deseo femenino con Lettere a Marina, como algo del orden de lo fluido, una "tromba marina", en este caso. El mar está siempre presente como metáfora que remite no solo a lo líquido sino a la falta de límites precisos, y es un "exponente del erotismo femenino" (Pertusa Seva, 2005, p. 107). La importancia de este erotismo que lleva a la protagonista a redescubrir su cuerpo y afirmarse como sujeto, ya no idéntico a los modelos y estereotipos del pasado, es un punto clave en la novela. Se trata de un deseo portador de un cambio fundamental en su persona: "erotismo... in termini di affermazione della forza vitale delle donne [erotismo... en términos de afirmación de la fuerza vital de las mujeres]" (Lorde, 1997, p. 250), y que se contrapone al "deseo domesticado" del psicoanálisis. Elena ya había adelantado anteriormente su acuerdo con las teorías del feminismo, aludiendo a un erotismo como potencial de cambio y a un deseo malinterpretado por la sociedad patriarcal:

Porque sí le parece a Elena que tienen razón las feministas, cuando afirman que, si bien un erotismo lo más liberado posible... puede actuar como fuerza revulsiva y, por lo tanto, creadora, la pornografía, por el contrario, lejos de liberar, lo que pretende es encorsetar la sexualidad dentro de un orden, y es ya realmente el colmo que creen para nosotros un esquema universal de sexualidad y nos impongan a presión unas torpes y burdas perversiones y unos desvaídos y desangelados prototipos fantasmas (Tusquets, 2005, p. 51).

No solo la práctica lesbiana puede ser vista como subversiva, dado que va en contra de la norma de heterosexualidad obligatoria, también puede transgredir el modelo una práctica heterosexual que deconstruya los roles o papeles asignados en función del género. Braidotti sugiere, por ejemplo, ampliando la teoría de Butler, que es necesario repensar una nueva forma de heterosexualidad (Braidotti, 2002, p. 52). Lo que hace la protagonista de Para no volver es revertir el rol pasivo que le correspondería como objeto del deseo masculino pasando a la acción. Como afirma Molinaro: "she then realizes that her desire and pleasure consists of resisting the passive role that she usually assumes and directing the game of love, provoking the resistance of the other participant... Her pleasure depends on his passivity [entonces ella se da cuenta 
de que su deseo y placer consisten en resistirse al rol pasivo que usualmente asume, y dirigiendo el juego del amor, provocando la resistencia del otro participante... Su placer depende de la pasividad de éll” (1991, p. 96).

En Lettere a Marina, Bianca recuerda las restricciones impuestas al cuerpo y la negación de la sexualidad durante su infancia y adolescencia, a través del discurso religioso del Colegio de Señoritas al que asistían: "mai mettere in mostra il proprio corpo mai toccarsi poi mai toccare le altre e cosi via era un catalogo di comandamenti che non finiva [jamás mostrar el propio cuerpo jamás tocarse además nunca tocar a las otras y así sucesivamente era un catálogo de imposiciones que no terminaba]" (Maraini, 2008, p. 55). El peso de estas prohibiciones genera, tanto en ella como en Marina, el deseo de rebelión: "tu non avresti questi desideri di incesto se non credessi ciecamente alla proibizione del rapporto madre-figlia... condizioni per la trasmissione della cultura [tú no tendrías estos deseos de incesto si no creyeras ciegamente en la prohibición del vínculo madre-hija... condiciones para la transmisión de la cultura]” (Maraini, 2008, p. 86).

Son estos "discursos correctivos", que prescriben una conducta corporal y codifican una pedagogía, los responsables de la implantación de las "perversiones" o "sexualidades periféricas", es decir, anómalas (Foucault, 2005, p. 43), pudiendo aplicarse esto tanto al lesbianismo como a la práctica de una heterosexualidad que deconstruye las conductas establecidas en función del género o invierte la correspondencia entre el activo-masculino y el pasivo-femenino, como en el caso de Para no volver. Aquí también entra en juego la religión, que se mezcla en la sesión psicoanalítica, Elena es vista por el Mago como "sacrílega"15 y él se presenta como un "Exorcista" que pretende curar su mal (Tusquets, 2005, p. 112). En Lettere a Marina, el "sacrilegio" de Bianca y Marina se da a partir de la proyección de ambas en el rol de streghe o brujas, en oposición a "la dolce Madonna del volto ebete e sottomesso [la dulce Madonna del rostro imbécil y sometido]" (Maraini, 2008, p. 167). De forma paralela, en Elena la crítica al eterno femenino radica en "una careta con dos expresiones distintas: los roles de mamá o de Beatriz" (Tusquets, 2005, p. 175), es decir, la mujer reproductora funcional al sistema, o la donna angelo, a la que se refiere Dante en la Commedia, prototipo de una pureza virginal semejante a la Madonna.

El lesbianismo, en tanto práctica sexual que niega de manera radical la funcionalidad reproductiva del cuerpo femenino, es percibido por la sociedad como una práctica contra-natura. Bianca cita a Charlotte Wolf, Amore e sessualità fra donne, para mostrar hasta qué punto las relaciones entre mujeres son todavía percibidas como una enfermedad: "è una ricerca per 'fare guarire' chi non sta

15 Tanto en Para no volver como en Lettere a Marina se establece un juego paralelo entre lo sagrado y lo profano, y las protagonistas presentan conductas que transgreden el carácter sumiso preferible para las mujeres en la religión cristiana, quedando, de este modo, en falta. Esta conducta, en ambos casos, es tildada de "sacrílega". 
al gioco sociale ricondurle alla 'normalità' [es una investigación para 'curar' a quienes no responden al juego social reconducirlas a la 'normalidad']" (Maraini, 2008, p. 89). En la novela encontramos también, a modo de intertexto, alusiones recurrentes a la vida de la poeta norteamericana Emily Dickinson, cuya sexualidad ha sido considerada por la crítica en términos ambiguos: "nessuno sa dire, se Emily abbia amato e chi abbia amato: Susan, Kate,... [nadie sabe decir si Emily amó ni a quién amó: Susan, Kate...]" (Maraini, 2008, p. 101).

El cuerpo y la sexualidad adquieren, en cada uno de estos casos, una importancia fundamental en la conformación de una subjetividad femenina que pretende librarse del yugo de la convención: "como si el cuerpo, siempre más sabio, más certero que el espíritu, hubiera dado por su cuenta su respuesta" -afirma Elena- (Tusquets, 2005, p. 181). En una entrevista con Paolo di Paolo, Maraini especifica las razones de esta necesidad que en las mujeres supone reconciliarse con su propio cuerpo: "per millenni il destino femminile è stato identificato con il corpo... la verginità, il matrimonio, la gravidanza, la maternità... Qualsiasi discorso, per una donna, si scontrava con questa realtà storica, questa presenza-assenza del corpo-parola, del corpo-linguaggio [por milenios el destino de las mujeres ha estado identificado con el cuerpo... la virginidad, el matrimonio, el embarazo, la maternidad... Cualquier discurso, para una mujer, se chocaba con esta realidad histórica, esta presencia-ausencia del cuerpo-palabra, del cuerpo-lenguaje" (Maraini, 2005, p. 47).

Entre los discursos corporales prescriptivos, el estereotipo del cuerpo bello aparece también en Lettere a Marina, y Bianca se coloca, de un modo más radical que Elena, en sus antípodas, oponiéndose a los modelos heredados de Rosalind Russell, Elizabeth Taylor o Esther Williams: "Ia mia cintura era stata accorciata varie volte mi si poteva stringere la vita con le mani la gonna mi cascava prendendomi sui fianchi la camicetta mi scivolava sulle spalle magri i seni piatti [mi cinturón había sido acortado varias veces se me podía rodear la cintura con las manos la falda se me caía sosteniéndose solo por las caderas la blusa resbalaba sobre mi espalda magra mis senos planos]" (Maraini, 2008, p. 93).

Tanto Maraini como Tusquets hacen hincapié en el reduccionismo que implica la naturalización de la belleza, históricamente adjudicada al cuerpo femenino, algo que constituye un dispositivo más de control y coloca a las mujeres en el lugar de objetos de la mirada masculina, restándoles capacidad de acción. Maraini afirma: "il corpo femminile però si trova molto stretto nel mito della bellezza che gli è stato cucito addosso e che l'accompagna come una maledizione lodata mille volte [el cuerpo femenino, sin embargo, se encuentra muy estrechamente vinculado al mito de la belleza que le han cocido encima y que lo acompaña como una maldición alabada mil veces]" (2005, p. 48). En la escritura de Bianca la deconstrucción de los estereotipos y su persistencia, alternan a lo largo de la historia epistolar mediante los recuerdos que ella va recreando. Su soledad voluntaria se ve perturbada por una figura masculina: Massimo, el hermano de su amiga Fiammetta, que busca refugio 
en aquella casa alejada por ser un perseguido político. Con él, Bianca abandona la autonomía que la desviaba de la norma y termina transformándose en una "perfetta casalinga nevrotica... sono tre giorni che praticamente non faccio altro che cucinare pulire e litigare con Massimo [perfecta ama de casa neurótica... hace tres días que prácticamente no hago otra cosa que cocinar limpiar y pelear con Massimo]" (Maraini, 2008, p. 142). Cuando este finalmente se va, desaparece la convención de los roles y ella regresa a su anterior estado de mujer sola, aunque no alcanza, sin embargo, una completa libertad. Mediante una operación reflexiva, el contenido de las cartas de Bianca alude a la materialidad de la novela: "mi piacerebbe scrivere un libro che sia una dolorosa riflessione sulla propria impotenza [me gustaría escribir un libro que fuera una dolorosa reflexión sobre la propia impotencia]" (Maraini, 2008, p. 84). Su escritura no hace más que postergar el reencuentro con Marina, manifestando toda su impotencia ante un deseo que ha decidido reprimir: "il solo desiderio rimasto: scriverti. E continuo a farlo [el único deseo que queda: escribirte. Y sigo haciéndolo]" (Maraini, 2008, p. 174).

En Para no volver, Elena, a diferencia de Bianca, decide liberar finalmente su deseo y esto la lleva a reapropiarse de su yo, revirtiendo incluso la relación asimétrica en las sesiones de psicoanálisis: "habla ahora con voz lenta y grave: 'estoy interpretando el papel de yo misma psicoanalizándome'" (Tusquets, 2005, p. 45). Ahora es ella quien decide y se encuentra dispuesta a elaborar un discurso afirmativo de sí misma y de su propio cuerpo. El Mago así lo manifiesta:

¿Y no se te ocurre... pensar que esa disponibilidad para el goce, esa recuperación que tú misma reconoces como inesperada, del orgasmo... pueda deberse a que has salido ya o estás a punto de emerger de lo más hondo de tu depresión? (Tusquets, 2005, p. 183).

El final abierto y ambiguo de la novela con la frase: "sabes una cosa, Mago, me voy a psicoanalizar" (Tusquets, 2005, p. 198) parece erradicar, de una vez por todas, la resistencia que Elena constantemente experimentaba hacia el modelo, no para sumirse en él, sino con la certeza de que ha encontrado una vía alternativa: "she willfully will assume both roles and psychoanalyze herself, entering into a self-aware dialogue [ella voluntariamente asumirá ambos roles y se psicoanalizará a sí misma, entrando en un diálogo consciente de sí]" (Molinaro, 1991, p. 99).

\section{Conclusión}

A través del análisis de Lettere a Marina de Dacia Maraini y Para no volver de Esther Tusquets, se ha intentado demostrar de qué modo las ideas y prácticas feministas de la época están presentes, a modo de intertexto, en las representaciones literarias.

En la primera novela, el pequeño grupo de autoconciencia, característico del feminismo italiano, es mencionado por la protagonista como encuentro 
semanal donde se discuten las restricciones lingüísticas que impiden una adecuada representación de las mujeres y la necesidad de inventar nuevas formas de expresión, siendo esto evidente incluso en la materialidad misma de la escritura. Las cartas escritas por Bianca subvierten la gramática mediante la ausencia de signos de puntuación, como si ella buscara mediante esta escritura experimental, el fluir de un lenguaje, en las antípodas de la convención, que la incluya o la represente como mujer.

En ambas novelas se rebate el modelo patriarcal del psicoanálisis, algo que también se encontraba muy presente en las teorías feministas de la década de 1980. En Lettere a Marina, se explicitan las ideas que transgreden las prohibiciones del incesto y el parentesco: la relación lésbica entre Bianca y Marina es asimilada a los papeles de madre e hija. Bianca, por su parte, recuerda el deseo incestuoso hacia su propia madre, lo cual establece un diálogo con las teorías que circulan en Diotima y la Librería delle Donne di Milano, en donde el referente materno -que no se reduce a la madre biológica- es necesario para conformar el imaginario femenino negado por la cultura patriarcal. Todo esto sitúa a Maraini, como afirma Bertoni:

Closest to a position similar to... that of Luisa Muraro and [the] practice of affidamento. Muraro, in effect, proposes a kind of maternal relationship between older and younger women... through which the older woman acts, effectively, as a guide to the younger [Cercana a la posición... de Luisa Muraro y la práctica del encomendarse. Muraro, en efecto, propone un tipo de relación materna entre las mujeres más viejas y las más jóvenes... mediante la cual, las primeras se conviertan, efectivamente, en guías para las segundas] (2005, p. 130).

En Para no volver, la protagonista, Elena, pone de manifiesto su resistencia a los discursos de Freud y Lacan encarnados por el Mago, que colocan a las mujeres en el lugar de carencia. Su búsqueda personal y profundo malestar se diluyen cuando logra liberar el deseo domesticado al interior de ese imaginario y afirmarse en la posición de sujeto. Es entonces cuando se apropia del discurso, rompiendo la relación asimétrica que la unía a su psicoanalista. El cuerpo es el principal vector de cambio, pues en él se materializa el deseo. Tusquets, más influenciada quizás por el feminismo de la igualdad, no manifiesta en su novela la imposibilidad de expresar la subjetividad femenina en términos lingüísticos, sino la necesidad de apropiarse de lo dado para iniciar la vía alternativa que transforme la pasividad en acción. En Lettere a Marina, Bianca ha decidido reprimir su deseo, alejándose de su amante. Aun habiéndose convertido previamente en un cuerpo resistente en contra de una sexualidad prescriptiva, el peso de la norma recae sobre ella: "ho deciso domani parto... A Ustica sarò ancora più lontana da te Marina [he decidido mañana parto... En Ustica estaré todavía más lejos de ti Marina]" (Maraini, 2008, p. 202). Maraini demuestra, de esta manera, que a pesar de los progresos que han contribuido a visibilizar a las lesbianas en la década de 1980, los tabúes persisten y la lucha por el derecho a la diversidad sexual y la 
construcción de identidades de género más flexibles y fluidas, deberá continuar en las décadas sucesivas.

\section{Referencias}

Agustín Puerta, Mercedes. (2003). Feminismo: Identidad personal y lucha colectiva: Análisis del movimiento feminista español en los años 1975 a 1985. Granada: Editorial Universidad de Granada.

Agustín Puerta, Mercedes. (2009). Claves del feminismo español en la Transición Política. Algunas hipótesis a debate. En Jornadas Feministas Estatales, en Granada. España: Coordinadora Feminista y Asamblea de Mujeres Mariana Pineda. Recuperado de http://www.feministas.org/spip. php?article120

Amorós, Celia. (1985). Hacia una crítica de la razón patriarcal. Barcelona: Antropos.

Amorós, Celia. (2008). Tiempo de feminismo: Sobre feminismo, proyecto ilustrado y postmodernidad. Madrid: Cátedra.

Bertoni, Roberto. (2005). Political and social commitment in some Italian novels in the 1990's. En Narrativa italiana recente/Recent Italian Fiction. Torino: Trauben Edizioni.

Birnbaum, Lucia Chiavola. (1986). Liberazione della Donna: Feminism in Italy. Connecticut: Wesleyan University Press.

Blanco Corujo, Olivia e Morant Deusa, Isabel. (1995). El largo camino hacia la igualdad: Feminismo en España 1975-1995. Madrid: Instituto de la Mujer.

Bocchetti, Alessandra. (1996). Lo que quiere una mujer: Historia, política, teoría. Escritos, 1981-1995. Madrid: Cátedra.

Braidotti, Rosi. (2002). Becoming woman, or sexual difference revisited. En Metamorphoses: Towards a materialist theory of becoming. Cambridge: Polity Press.

Butler, Judith. (2002). Los cuerpos que importan. En Cuerpos que importan: Sobre los límites materiales y discursivos del "sexo". Buenos Aires: Paidós.

Butler, Judith. (2007). Sujetos de sexo/género/deseo. El género en disputa: El feminismo y la subversión de la identidad. Barcelona: Paidós.

Featherstone, Mike y Hepworth, Mike. (1999). The mask of ageing and the postmodern life course. En Mike Featherstone, Mike Hepworth y Bryan S. Turner (eds.), The Body: Social Process and Cultural Theory. London: 150 Sage Publications. 
Folguera, Pilar. (1988). De la transición política a la democracia. La evolución del feminismo en España durante el período 1975-1988. En El feminismo en España: Dos Siglos de Historia. Madrid: Editorial Pablo Iglesias.

Foucault, Michel. (2005). La implantación perversa. En Historia de la sexualidad: La voluntad de saber. Vol. 1. Madrid: Siglo Veintiuno.

Guerra, Elda. (2008). II femminismo italiano nel contesto degli anni Settanta. En Storia e cultura politica delle donne. Bologna: Archetipilibri.

Irigaray, Luce. (1974a). Una relación sexual impracticable. En Speculum: Espéculo de la otra mujer. Madrid: Saltés.

Irigaray, Luce. (1974b). Toda teoría del sujeto se ha adecuado siempre a lo 'masculino'”. En Speculum: Espéculo de la otra mujer. Madrid: Saltés.

Irigaray, Luce. (1987). Etica della differenza sessuale. Milano: Feltrinelli.

Irigaray, Luce. (1990). This sex which is not one. New York: Cornell University Press.

Irigaray, Luce. (1992a). El olvido de las genealogías. En Yo, tú, nosotras. Madrid: Cátedra.

Irigaray, Luce. (1992b). Escribir como una mujer. En Yo, tú, nosotras. Madrid: Cátedra.

Jones, Ann Rosalind. (2001). Escribiendo el cuerpo: Hacia una comprensión de la Écriture Fémenine. En Marysa Navarro y Catherine R. Stimpson (eds.), Nuevas direcciones. Buenos Aires: Fondo de Cultura Económica.

Jourdan, Clara. (2006). Luisa Muraro. Madrid: Ediciones del Orto.

Librería delle Donne di Milano. (1987). Non credere di avere dei diritti: La generazione della libertà femminile nell'idea e nelle vicende di un gruppo di donne. Torino: Rosenberg \& Sellier.

Lonzi, Carla. (1970). Sputiamo su Hegel. La donna clitoridea e la donna vaginale. Milano: Scritti di Rivolta Femminile.

Lorde, Audre. (1997). Usi dell'erotismo: l'erotismo come potere. En: R. Baccolini, M. G. Fabi, Vita Fortunati e R. Monticelli (eds.), Critiche femministe e teorie letterarie. Bologna: CLUEB.

Maraini, Dacia. (2005). Ho sognato una stazione: Gli affetti, i valori, le passioni. Conversazione con Paolo di Paolo. Roma: Laterza.

Maraini, Dacia. (2008). Lettere a Marina. Milano: BUR.

Molinaro, Nina L. (1991). Foucault, Feminism and Power: Reading Esther Tusquets. New York: Associated University Press. 
Muraro, Luisa. (1991). L'ordine simbolico della madre. Roma: Editori Riuniti.

Pertusa Seva, Inmaculada. (2005). La salida del armario: Lecturas desde la otra acera. Esther Tusquets, Carme Riera, Sylvia Molloy, Cristina Peri Rosi. Gijón: Llebros del Pexe.

Properzi Nelsen, Elisabetta. (2000). Écriture Féminine as Consciousness of the Condition of Women in Dacia Maraini's Early Narrative. En Rodica Diaconescu-Blumenfeld y Ada Testaferri (eds.), The pleasure of writing: Critical Essays on Dacia Maraini. Indiana: Purdue University.

Posada Kubissa, Luisa. (1998). Sexo y esencia. De esencialismos encubiertos y esencialismos heredados: desde un feminismo nominalista. Madrid: Horas y Horas.

Puccio, Rosella. (2006). Identità e parola: intervista a Dacia Maraini. Balarm Magazine. Recuperado de http://www.balarm.it/articoli/Vis.asp?ldArticolo $=3335 \& \mathrm{ld}$ Categoria $=36$

Sumeli Weinberg, M. Grazia. (1993). Invito alla lecttura di Dacia Maraini. Pretoria: University of South Africa.

Tusquets, Esther. (2005). Para no volver. Barcelona: Anagrama.

Tusquets, Esther. (2006). Prefiero ser mujer. Barcelona: RqueR.

Tusquets, Esther. (2009). Confesiones de una vieja dama indigna. Barcelona: Bruguera.

Waithe, Mary Ellen. (1992). A History of Women Philosophers. Vol. 1. Netherlands: Klwer.

Wittig, Monique. (1977). El cuerpo lesbiano. Valencia: Pre-textos. 